\title{
Plastic Packaging: A Study on Plastic Imports in Uganda
}

\author{
Cynthia Mutonyi Wandeka, Nicholas Kiggundu, Raymonds Mutumba* \\ Department of Agricultural and Biosystems Engineering \\ Makerere University, P. O. Box 7062, Kampala, Uganda
}

*Corresponding author details: Raymonds Mutumba; raymondmutumba@gmail.com

\begin{abstract}
Plastic packaging is crucial in preserving the quality of products. It has become ubiquitous, and an inseparable part of daily life and the food industry due to its aesthetic attributes, strength, affordability and convenience of use. This has thus led to the increase in demand and imports of plastics in the country. However, plastic packaging alone accounts for $47 \%$ of global plastic waste amidst documented threats of plastic waste to the environment-water-food-health nexus. Several reports indicate that between 1994 and 2017, Uganda imported a total of 1.9 million tons of plastic in both raw and finished form compared to 117 million tons across Africa. Imports and use of plastics in Uganda have increased by six-fold within the last three years hence extrapolating the growing challenge for sustainable plastic imports, product packaging, and waste management. The objective of the review therefore was to explore the future trend and impact of plastic imports and packaging in Uganda by analyzing plastic imports and the associated waste. The study further reviews the challenges arising from the growing demand for plastic packaging and presents a discussion on the solutions and potential ways forward for win-win benefits. Several strides to curb the menace of plastic waste are presented, which are manly from the private sector and plastic recycling businesses. A conclusion is made that if these efforts are to meet the intended leaps of change, the government of Uganda has to support the private organisations through grants, space allocation for collection centers and media access across the country. Furthermore, stricter regulations on excess plastic importation have to be implemented by the government as the country develops locally grown solutions to plastic packaging and use.
\end{abstract}

\section{Keywords: plastic imports; plastic packaging; waste management; sustainability; Uganda}

\section{INTRODUCTION}

Plastics have been in existence from as early as the mid19 th century and have since become common materials for use globally especially in the packaging industry (Porta, 2019). In 2015, the production of plastics had reached 407 million tons per annum globally (OECD, 2018) exceeding the production of paper (400 million tons) and Aluminum (57 million tons) which are immediate substitutes for plastic use. Since the beginning of the commercial production of plastics from 1950, 7.8 million tons of plastics have been produced indicating one ton of plastic per person to date (Geyer et al., 2017). The production and use of plastics globally is expected to reach 1,600 metric tons in 2050 and production continues to grow at the same rate (Liu et al., 2018). This is due to their unique functionality and thus they cannot be easily substituted with available alternatives like glass or paper. Common applications of plastic include food containers, soft drink and water bottles, milk jugs, water jugs and film products like bags and sacks (Raheem, 2013). Uganda imports approximately $8,768,103$ tons of plastic currently (URA, 2019). This is a large increase in comparison to the $1.9 \mathrm{Mt}$ of plastic in different forms between 1994 and 2017 a small percentage of the $86.14 \mathrm{Mt}$ imported in Africa (Babayemmi et al., 2019). According to Nampijja, (2016) imported plastic packaging materials constitute about 80$90 \%$ of the packaging material used in Uganda and this is expected to increase. This is mainly because of strong consumer demand and market trends which have expedited adoption of more creative and advanced plastic packaging technologies. Considering developmental plans across Africa, and the already observed years of strong economic growth (ranging from 8-12\% in 2012) through value addition to agricultural products and increased export to European countries (Kornher et al., 2020), there is clearly going to be an increase in the demand for plastic packaging imports as well as an increased in country production.

The challenge associated with this increase in imports combined with growing in-country production of plastic packaging material is that it's going to add more pressure to an already struggling waste management system. According to research published in a 2011 policy paper by Water Aid in Uganda and other environmental and sanitation groups, 1,200 to 1,500 tons of garbage are generated each day in Kampala, but only 400 to 500 tons are collected. The scale of the challenge is large i.e., each day, Uganda generates around 600 metric tons of plastic waste and estimates show that Kampala Capital City Authority spends $\$ 1.53$ million per month to remove only 30 percent of the total waste generated. Uganda has previously banned the use of single-use plastics but enforcement measures have not been affected and since China and India are no longer buying plastic waste, there's little demand (Vanapalli et al., 2021). The recycling companies that used to shred the bottles and other plastic waste and export the flakes now have nowhere to send all their plastic and its now just piling up and overflowing out of their gates and all over the streets because much of the plastic waste produced especially bottles can't be recycled in Uganda. There are many ideas and private companies being created to reduce this waste in addition to the overutilized government landfill in Kiteezi, Kampala Uganda. 
These include Takataka Plastics in Gulu, Eco Ways Uganda in Mbarara, Eco plastics in Kampala as well as some externally funded groups like Eco Brix in Masaka among others. However, these companies cannot singularly handle the amount of waste being generated. This simply put means a ban on imports of use of plastics may not be the best way forward. Construction of more materials recovery facilities is a major need in all these countries especially Uganda and so is the strict application of the re-duce, reuse and recycle principles in plastic waste management however these methods alone may not also be sufficient to handle the growing waste problem. This paper suggests that more effort needs to be placed in more sustainable and long-term programs to handle this potential future mess and that is Education. Education is a long-term plan and its effect may not be seen as clearly or quickly as cash rewards for plastic waste collection and sales. However, it is evident that this mixed plastic waste handling approach being utilized in more developed countries like the USA and Europe to ensure the sustainability of improvements will be more effective and create a higher chance of reduction of plastic waste being dumped in the environment and eventually higher chances of a balanced import, production and waste management plan.

\section{CLASSIFICATION OF PLASTIC PACKAGING IMPORTED INTO UGANDA}

Plastic packaging are materials associated with use of plastic material or container to provide proper storage and to protect the product from the environment (Wrona and Nerin, 2020). Plastic packaging is vital in food waste reduction since it extends the shelf life of the food and also helps reduce transportation costs by bringing the packaging weight down.
As modernity continues to take over, packaging has also developed especially in the area of food safety and maintaining the high-quality of food products for consumer consumption (Kotsanopoulos and Arvanitoyannis, 2017). Plastic packaging imported into Uganda and other African countries can be classified into a series of materials depending on the end use (Bashir, 2013).

The different types of plastic packaging imports include; Polyethylene Terephthalate (PET) commonly used for soda bottles, cooking oil bottles, and peanut butter jars among others. High Density Polyethylene (HDPE) is commonly used for detergent bottles, milk jugs, grocery bags among others. Polyvinyl Chloride (PVC) is commonly used for plastic pipes, outdoor furniture but also shrink wrap, water bottles, salad dressing and liquid detergent containers among others. Low Density Polyethylene (LDPE) are another type commonly used for dry cleaning bags, produce bags, trash can liners, food storage containers and finally Polystyrene (PS) commonly used for packaging pellets or "Styrofoam peanuts," cups, plastic tableware, meat trays, to-go. In Uganda, many of the classified materials are imported in the form of spools, cops, bobbins and similar supports of plastics used in the textile industry largely followed by carboys, bottles, flasks, food wrappers, plastic grocery bags, plastic lids, straws and foam take-away containers among others (Table 1). Styrofoam which is mostly used for producing food containers is highly imported because of its rigidity, lightweight and good insulation properties. Polyethylene Terephthalate PET or PETE) is tough, light, flexible and thus best for making shopping bags (Ojha et al., 2015).

TABLE 1: Types of plastic packaging imported into Uganda

\begin{tabular}{|c|c|c|}
\hline Type of packaging & Quantity & Cost in UGX \\
\hline Inserts & 1,409 & $39,020,138$ \\
\hline Sacks \& bags of other plastics (bags for the foods \& drinks) & 5,131 & $127,580,878$ \\
\hline Plastic tubes for packing of toothpaste, cosmetics and others & 26,734 & $459,134,476$ \\
\hline Empty gelatin capsules for pharmaceutical use & 38,550 & $3,745,497,426$ \\
\hline Sacks and bags (incl. cones) of polymers of ethylene & 113,827 & $968,794,786$ \\
\hline Sacks and bags (incl. cones) of other plastics (excl. ethylene) & 282,582 & $2,898,238,071$ \\
\hline Boxes, cases, crates and similar articles of plastics & 771,308 & $7,469,082,989$ \\
\hline Other stoppers, lids, caps and other closures & $1,372,011$ & $16,775,906,904$ \\
\hline Articles of conveyance or packing of goods, of plastics & $1,444,191$ & $10,578,611,642$ \\
\hline Spools, cops, bobbins and similar supports of plastics & $4,712,360$ & $24,005,171,359$ \\
\hline Carboys, bottles, flasks and similar article & $3,504,858$ & $28,247,356,190$ \\
\hline
\end{tabular}

Source: Uganda Revenue Authority 2020

Apart from the PET, PVC and HDPE, other types of plastic imported are not accepted by many of the recycling companies and thus single use plastic packages are used to carry goods and are usually provided to customers at the point-of-sale. Other kinds like cups, meat trays, Tupperware and other containers that have come in contact with food are difficult to recycle. These plastics that are seldom accepted by recycling companies pose the greater problem in Africa (Bashir et al., 2013).

\section{PLASTIC PACKAGING INDUSTRY IN UGANDA VERSUS NEIGHBORING COUNTRIES}

Growth and increase in plastic packaging imports and incountry manufacturing plants, as well as the clear economic opportunities surrounding the plastic packaging industry, have not only been observed in Uganda but many other African countries for example Ghana, Egypt (importing 43
Mt, 18.7\%), Nigeria (importing $39 \mathrm{Mt}, 17.0 \%$ ), Algeria (importing $26 \mathrm{Mt}, 11.3 \%$ ), Morocco (importing $22 \mathrm{Mt}, 9.6 \%$ ), Tunisia (importing $16 \mathrm{Mt}, 7.0 \%$ ) among others (Babayemi et al., 2019). During the past six years the use of plastics in Africa has grown by an astounding $150 \%$, at a compound average growth rate of approximately $8.7 \%$. Imports into Africa have grown between $23 \%$ and $41 \%$ during this time and analysts predicted that the use of plastics in East Africa alone is expected to triple in the next five years (Bashir, 2013).

In Uganda, it is estimated that approximately 600 tons of plastic packaging is consumed every day and that a person uses up to $43 \mathrm{~kg}$ of plastics annually (CARE, 2019). The arising demand of plastic packaging is being accelerated by the rise in the population and also medium and small-scale industries that need packaging (Ggoobi, 2020). 
The population of Uganda has grown up to 43.8 million people from 37.4 million people in 2017 with a GDP of \$ 956.9 (UBOS, 2019). The increasing population with growth in GDP subsequently leads to an increase in household income and hence purchasing power for plastic packaging (African Union, 2017). The Economic Research Department, 2019, also reported that as the number of single-person households increases, the demand for small packaging also increases which translates into relatively more packaging material per unit of the product. And this increase in population growth together with urbanization will result in the emergency of larger consumer markets.

It has already been observed that Kampala, the business center of Uganda, has become a center for the packaging industry as more and more manufacturing units are being set up in and around the city to meet the rising demand for plastic goods like melamine utensils, plastic household foods, plastic bags, toothbrushes among others. Nice House of Plastics being one of the larger players in the plastics industry in Uganda followed by Riley Packaging in Mukono, Afro-plast Enterprises Ltd in Luzira, General Molding in Industrial Area, Rwenzori Bottling Company among others (Aryampa et al., 2019). The Uganda Business Impact Survey done in 2020 also showed that MSMEs collectively constitute about $90 \%$ of private sector production in Uganda and employ over 2.5 million people. Among these, the highest proportion of MSMEs work in the agricultural sector $(14 \%)$, followed by the education \& health sector (13\%), and recreation \& personal (10\%).

Most of the companies dealing in the agricultural sector i.e., over $10 \%$ are concentrated on adding value to agricultural produce, not forgetting the large percentage under the recreation and personal category dealing in personal care and beauty products and the second largest need of all these companies after funding is marketable packaging material to boost promotion of developed products. The Government of Uganda (GoU) has also emphasized the opportunity to implement the import substitution approach in many sectors (Ggoobi, 2020). Being a landlocked country, Uganda also imports a majority of its plastic and packaging requirements from regional and international suppliers and has thus emerged as a major importer of plastics in the East Africa region. This shows that the country is heading towards more in-county production of packaging material primarily plastic because of its many competitive properties which will increase plastic packaging on the market and consequently plastic waste.

The same trend can be observed in other African countries for instance, plastics consumption per capita in Kenya was just $10 \mathrm{~kg}$ in 2004 and it was expected to increase to $20 \mathrm{~kg}$ by 2015 . This is still very low compared to many other countries in other parts of Africa (Babayemi et al., 2019). Currently, the import of plastic materials and resins into Kenya being boosted by demand and thus has grown steadily in the last two years, an average rate of $10-20 \%$ annually. This is mainly because economic reforms that have led an overall economic development in many sectors and subsequently improved disposable incomes of the middle-class in Kenya (Elliott et al., 2018). This demand is expected to increase alongside demand for machinery as Kenya's enterprising business community embarks on strengthening the country's manufacturing base. Some of the companies in the plastics and packaging industry in Kenya include: Dodhia Packaging Limited, Statpack Industries Limited, Uni-Plastics Ltd., and East African Packaging Industries Limited (EAPI). This incremental trend is expected to worsen the negative effect of plastics to the environment.
Tanzania on the other hand is one of the largest markets for plastics and packaging goods in the East Africa region. The country has been importing plastic goods and machinery from across the world in increasing quantities over the last five years and has emerged as a lucrative market for plastic goods in the region (Wangwe et al., 2014).

\section{CHALLENGES ARISING FROM PLASTIC IMPORTATION IN UGANDA}

The plastic packaging industry is one of the fastest growing industries in Uganda (Goobi, 2020). And as African economies strive more towards independence and more economic self-reliance, this trend is going to increase further. Although economic predictions look attractive, there are many challenges that exist and are going to continue to grow with these developments. Some of the many challenges facing the Africa plastics industry include domestic production being supplemented by imports and thus no significant profits, continued lag behind developed countries due to unadvanced production methods, product quality, the scale of production and product range, the conservative attitude of manufacturers and consumers towards new materials, poor government support (and the strong position of the metals industry), a shortage of good infrastructure to boost manufacturing not forgetting the unpreparedness of many of these African countries to handle the waste that is and will continue to be generated by this industry (Mwanza and Mbohwa, 2017). The effect and evidence of plastic wastes in Uganda is noticed in the major cities of the country including Kampala and Wakiso. This can be attributed to the fact these are the most populated cities with high levels of product consumption, trade hence high plastic waste generation. The graph below shows the distribution of generated plastic wastes in major cities in Uganda (Owusu et al., 2017).

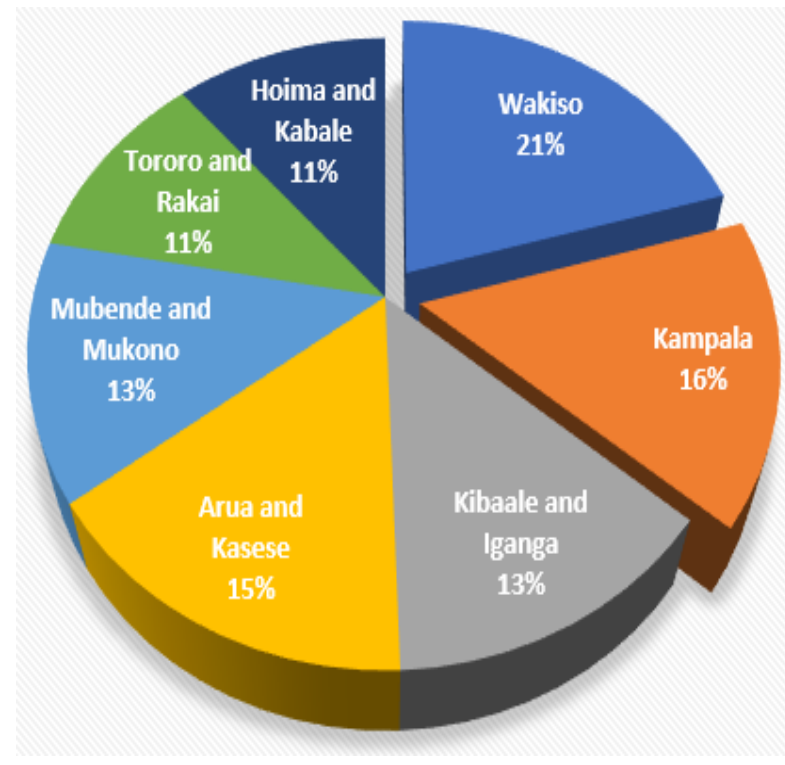

FIGURE 1: Estimated number of plastics generated in major districts in Uganda

Plastic being nonbiodegradable and considering the fact that not all types of plastic are easily recycled, accumulation in the environment is an obvious outcome and if not properly managed will lead to the creation of mountains of waste. All these are highly detrimental to public health, causing high rates of pollution, making land inhabitable, and contaminating the soil leading to soil degradation among others. 


\section{PLASTIC PACKAGING DISPOSAL AND RELATED IMPACTS IN UGANDA}

When the packaging has finished its use, it is recycled, incinerated, reused, dumped in the landfills or littered in the environment. Approximately $79 \%$ of plastics are dumped into the landfills or environment, $12 \%$ are incinerated while 9\% is recycled (Geyer et al., 2017). According to a study on household's responsiveness to the ban on plastic carrier bags by Mugisha and Diiro (2015), $48 \%$ of the households were found to dump polythene bags in the unused neighboring spaces, $18 \%$ dumped in the rubbish pits while $26 \%$ packed them well in a bigger plastic bag before dumping at the universal city dumping center. Some of the reasons for improper dumping of plastic bags included long distances to the dumping sites and high charges by the waste collectors. The large percentages of single use plastics dumped into the environment indicate the failing waste management systems. The disposal of packaging material should be done in a way that will not have a negative impact on humanity, the ecosystem and the environment.

\section{(1) Plastic packaging impacts on the environment in Uganda}

Uganda is part of the Great Lakes region with its largest freshwater ecosystem as Lake Victoria. This waterbody shared with Kenya and Tanzania is the source of the River Nile that flows 6,695 kilometers before ending in the Mediterranean Sea. However, Lake Victoria and its related ecosystems are threatened by the disastrous effects of the triple planetary crises; biodiversity breakdown, a climate emergency and rampant pollution (UNEP, 2021). This emanates from years of unregulated importation, irresponsible consumption, inefficient production and insufficient plastics waste disposal. A recent study by UN Environmental Program shows that about 1 in 5 of the fish in Lake Victoria had ingested plastic while another research indicated microplastics in surface waters in several sites on the lake. This detrimental effect of plastic wastes degrades the ecosystem services and threatens the health and livelihoods of the communities that depend on the lake for survival.

Plastic packaging bags in high concentrations have been found to block the airways and stomachs of several marine animals in different water bodies in Uganda. According to (UNEP, 2018), 15\% of marine species have been affected by plastic ingestion. When in water, these plastic bags look like jellyfish and they are often ingested by dolphins and turtles which mistake them for food. When producing plastic bags, a number of chemicals such as plasticizers and colorants are added to improve their properties. These chemicals are later dissolved into the animal's tissues after ingestion and end up entering into the food chain for human beings.

According to the National Health and Nutrition Examination Survey, $6 \%$ of 16 to 49 -year-old women were found to have methyl mercury in their blood which is a neurological toxicant found in fish after ingesting plastic bags (Center for Disease Control, 2006).

Microplastics have been found to already exist in table salt and in both tap and bottled water (Kosuth et al., 2019). Of the 159 globally sourced samples of tap water, $81 \%$ were found to contain synthetic particles. The results indicated that on average a person ingests over 5,800 particles of synthetic debris from tap water, beer, and table salt with the largest contribution (88\%) coming from tap water. Plastic packaging is produced from fossil fuels and this has a significant impact on the carbon concentrations in the atmosphere. Over $90 \%$ of the plastics are derived from virgin fossil fuels and this represents about $6 \%$ of the global oil consumption which is equivalent to the oil consumption of the global aviation sector. With the continued use of plastics, the plastics sector will account for $20 \%$ of the total oil consumption and $15 \%$ of the global annual carbon budget by 2050 up from the $1 \%$ of the present (WEF, 2016). These figures are so crucial in addressing the effect of greenhouse gases.

Microplastics in Uganda have been known as a source of pollution to the soil. This could have a long-term damaging effect on terrestrial ecosystems globally through adverse effects on microorganisms such as soil-dwelling invertebrates and fungi. Such microorganisms are needed for important ecosystem services and functions. Approximately 895 microplastic particles per kilogram have been found in organic fertilizers used in agricultural soils (Abel et al., 2017). This has potential direct effects on soil ecosystems, crops and livestock due to the presence of toxic chemicals. In Kyangwali which is a refugee settlement in Uganda, one ton of plastic waste is estimated to be generated per week (CARE, 2019). Much of this waste is from water bottles, packaging bags, food wraps and utensils in cities like Kampala. The majority of this waste is not collected and is lay scattered on the ground being blown by the wind. This leads to pollution of the households, agriculture, compositing systems and open waterways. The limited amounts of plastic packaging collected is burnt in the open causing hazardous pollution risks.

According to NATURES (2021), 8.6 million pieces of preform PET bottles are imported into Uganda per day, of which $40 \%$ (3.4 million pieces) are commercialized in the Greater Kampala Metropolitan Area (GKMA) every day. This equals an amount of 62.9 tons/day of plastics. Of this, $57 \%$ of the PET plastic waste this generates is collected, $17 \%$ ends up at gazette disposal sites, $35 \%$ is transported to recovery facilities where it is processed for exportation and $5 \%$ is leaked during collection and transportation services as indicated in Figure 2. 43\% of all PET waste is NOT collected which corresponds to 9.948 tons of uncollected plastic per year. This faction may end up in drains, land and water bodies. 


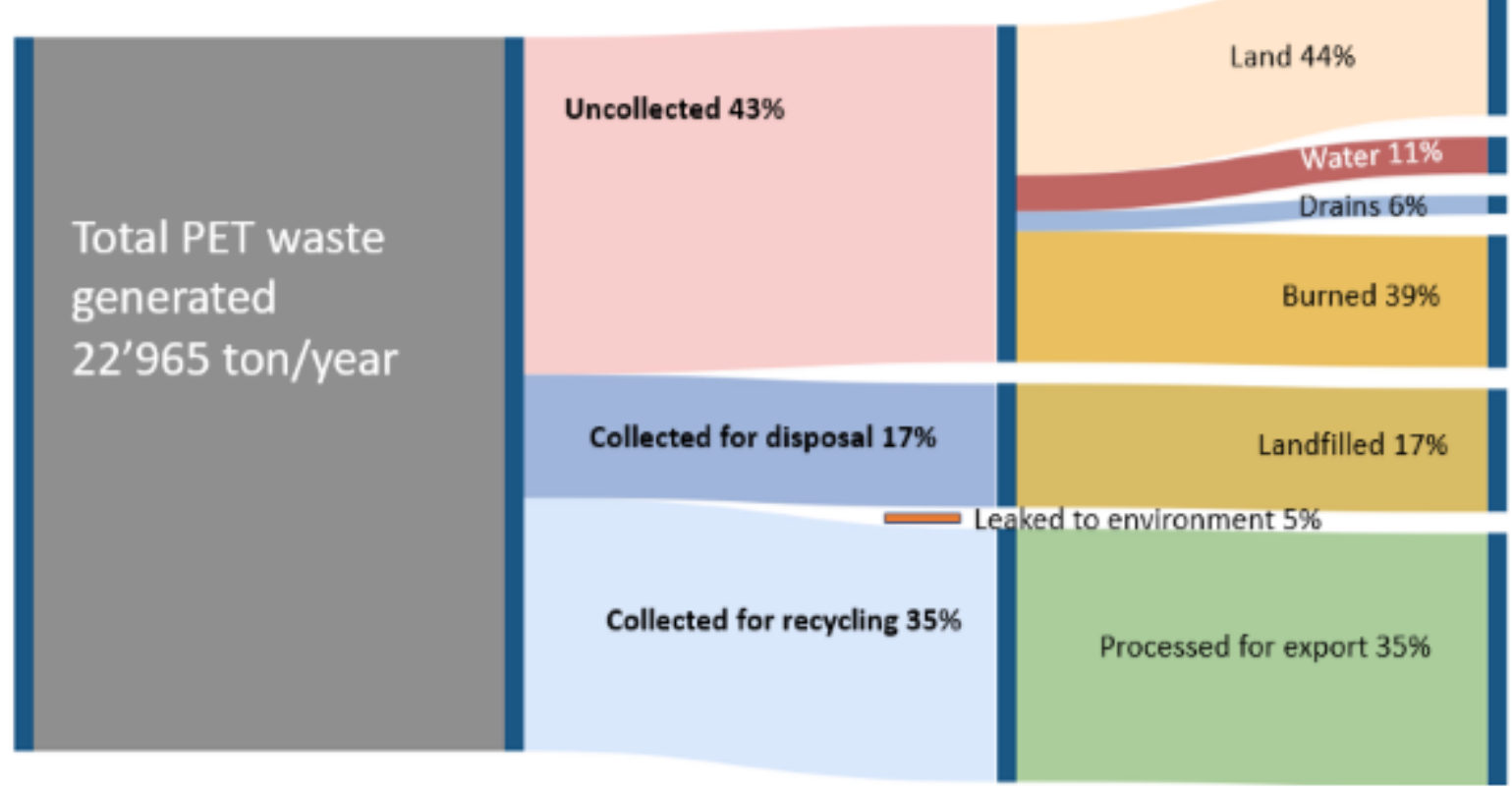

FIGURE 2: PET waste flows in GKMA visualized using a Sankey diagram. (NATURES, 2021)

These statistics indicate significant generation of plastic waste and pollution in Greater Kampala and Metropolitan Areas. Littering and of illegal dumpsites results into negative impacts like degradation of landscapes and blockage of urban canals and rivers. Increased risk of flooding and the emergence of waterborne diseases in stagnant waters are ultimate consequences.

\section{(2) PLASTIC PACKAGING IMPACTS ON HUMANS}

Plastic bags are a breeding ground for mosquitoes and other pests and this increases the transmission of vector borne diseases such as malaria (Rayne, 2008). It is estimated that about 500 million to 1 trillion plastic bags are produced globally each year and their uncontrolled disposal into the environment makes them a breeding ground for mosquitoes (UNEP, 2018). During the manufacture of plastic bags, various chemicals such as plasticizers, stabilizers and colorants are added some of which end up being toxic when they enter into the human body (Tucker et al., 2016). Some of the dangerous products include Styrofoam which has carcinogenic chemicals such as styrene and benzene that are transferred to food and drinks and this becomes severe when food is reheated in that container. These toxins damage the nervous, respiratory and reproductive systems when ingested. Plastic bag waste is usually burnt for cooking in some areas of the world and they produce toxins like furan and dioxin. This utilization of plastics exposes mostly women and children to prolonged toxic emissions since they are mostly involved in cooking. Other safer means of lighting stoves or energy sources, therefore, have to be implemented in order to reduce this life-threatening impact of plastics.

(3) PLASTIC PACKAGING IMPACTS ON THE ECONOMY Although plastics have become a workhorse material of today's economy, $95 \%$ of the plastic packaging value which is equivalent to $\$ 80-120$ billion is lost annually after their first use of cycle (WEF, 2016). More so $32 \%$ of the plastic packaging escapes collection systems which cause significant costs to the economy because it affects natural systems like oceans and clogs urban infrastructure. The cost related to the above effects of plastic packaging including that associated with the greenhouse gas emissions from its production is approximately $\$ 40$ billion annually. This cost exceeds the profit pool of the plastic packaging industry.
Approximately $14 \%$ of the plastic packaging is collected for recycling and when additional value losses in sorting and reprocessing are included only $5 \%$ of the material value is retained for subsequent use (WEF, 2016). Recycled plastics are usually of lower value application and are not recyclable again after use. After all, the recycling rate for plastic packaging is far below the global recycling rates for paper (58\%) and iron and steel (70$90 \%$ ). Plastic packaging is almost entirely single use especially in business to consumer applications. Dropping plastic bags on the environment leads to perceived welfare losses associated for instance to the visual disadvantage of a park being contaminated with litter. This is common in developing countries as well as developed countries and this increases the indirect social costs of plastic pollution. According to Sherrington, Hogg, Darrah, and Hann, (2014) a cost of \$60-120 million was wasted in removing the beach litter. Research from the Asia- Pacific Economic Cooperation found out that plastics had an economic impact of $\$ 1.3$ billion to the tourism, fishing and shipping industries. Some plastic packaging is so challenging that it cannot be recycled and though this may be possible but it is economically not unviable (Maharan and Negi, 2007). Styrofoam products where $95 \%$ of the product is air and so is difficult and not cost effective to ship or store for recycling. The amount of packaging in a regular shopping basket, even if collected, $21-40 \%$ cannot be effectively recycled (Hopewell et al., 2009). Since Uganda has local plastic manufacturers, unregulated importation of plastic wastes into the country creates an unemployment dilemma since manufacturing factories employ a huge number of both workers. Increase in local production of plastics would also increase plastic export out of the country hence boosting revenue inflow.

\section{CURRENT WASTE MANAGEMENT SOLUTIONS FOR PLASTIC PACKAGING IN UGANDA}

Plastic packaging is of great importance to the economy although strong action needs to be taken to avoid or control the waste generated from this industry in Uganda. This will help reduce its negative impact on human life and the environment. Many African countries have created plastic waste management systems but the plastic waste challenge continues to grow anyway. 
Some of the solutions earlier solutions employed to reduce plastic waste in Uganda (2007), Kenya, Tanzania, Rwanda, Ghana as well as many other African countries, included the ban on the production and use of polythene carrier bags of less than 30 microns, imposing heavy excise duty $(120 \%$ for Uganda) on thicker polythene materials, collection and sell to other countries that buy plastics among others (Goobi, 2020; Debrah et al., 2021). But these didn't record large improvement because of rejection for economic and political reasons. Their effectiveness in addressing the targeted problem remains questionable because it is a partial instrument that is difficult to apply (Mugisha \& Diiro, 2015). To date polythene packaging bags are still in use especially in small retail shops and in markets. In the same study, $83 \%$ of the respondents suggested that the easiest measure to enforce and strengthen this law is by putting a complete ban on all plastic bags as it was done successfully in Rwanda (Danielsson, 2017). Furthermore, the environment and natural resources $\mathrm{CSO}$ in Uganda have supported community-based initiatives to promote the 3R (Reduce, Re-use, Recycle) concepts and principles to waste management along the generation value chain.

In South Africa, the decision by the government to put a ban on polythene packaging bags thinner than 80 microns caused havoc among the trade unions and business communities. Therefore, the government decided to compromise to a thickness of 30 microns (UNEP, 2018; Mugisha and Diiro, 2015). Kenya also didn't record much success even after placing the most severe plastic bag ban in the whole world with offenders facing fines of up to $\$ 350$ or four- year jail (NEMA, 2017). Before the year 2017, about 100 million plastic bags were still being used in Kenya every year and this was only in supermarkets but the country still ranks worst in East Africa. In more recent times newer technologies have been adopted and are registering more significant reduction in plastic waste on the streets however these are still lacking. South Africa stands at the fore-front recycling around $13 \%$ of original plastic produced annually, all this mostly recovered as post-consumer waste i.e., 30\% of actual packaging polymers produced. There is also high demand for the conversion technologies like extruder, injection molding, blow molding, rotor-molding and thermoforming. And being a developed country, plastics recycling and environmentally friendly plastics are considered important for the plastics industry in South Africa.

Other countries like Ethiopia with the Indian and Mauritian joint venture which concentrates on the production of fuel from waste plastics using new technology have also excelled through the construction of one of the large factories using Professor Alka Umesh Zadgaonkar's innovation, turning all plastic materials (PVC) into fuel within four hours of processing (Raja et al., 2011) This technology has enabled production of the same/equivalent weight of fuel from the similar weight of waste plastics and it's being used for various applications such as jet fuel. India alone reported saving approximately US $\$ 3.8$ billion every year usually spent on importing fuel produced from crude oil by using this technology and this has informed extension of the same system to other countries such as Ghana, Mauritius and Tunisia. And there's hope of replication to other African countries where interest lies. Thermoplastic starch is also already in use to protect packaged goods in transit. Research has been on going to see if the use of starch could replace Styrofoam especially for food packaging. The research has mainly focused on cassava an important staple in Asia, Africa and South America (World Environment Day, 2018) although this is not yet universally embraced. A point to note is that reducing on the usage of plastic packaging is

more feasible as compared to completely replacing them (ACC, 2019). Replacing plastic packaging with alternatives would mean using more energy (80\%) and creating more greenhouse gases $(130 \%)$. The impacts of plastic packaging can be reduced by transforming and strengthening markets for recycled plastics (WEF, 2016). This can be done by introducing and scaling up matchmaking mechanisms for example using aggregator software or platforms to include companies not yet participating in the recycled plastic markets. This should include both small processing companies and those that source recycled content at the small to medium scale.

In Uganda, several strides have been made to reduce the impact of plastic waste by recycling as much plastic as possible. Initiatives like the Taasa Obutonde meaning "Save Nature" have been started by private enterprises that feel the need to do something about plastics. Other private companies like Vivo Energy Uganda have partnered with Plastic Recycling Industries Limited, an initiative of Coca-Cola Beverages Africa in Uganda (CCBA), to routinely collect plastic waste from over 167 Shell service stations countrywide for recycling purposes (Vivo Energy Uganda, 2021). Other locally grown solutions include Takataka which means "waste" in Swahili is focusing on using the plastic for construction materials as shown in Figure 3. Uganda has a huge housing shortage, and the Ugandan construction industry is growing in excess of 10 percent annually, making this a growing market for materials.

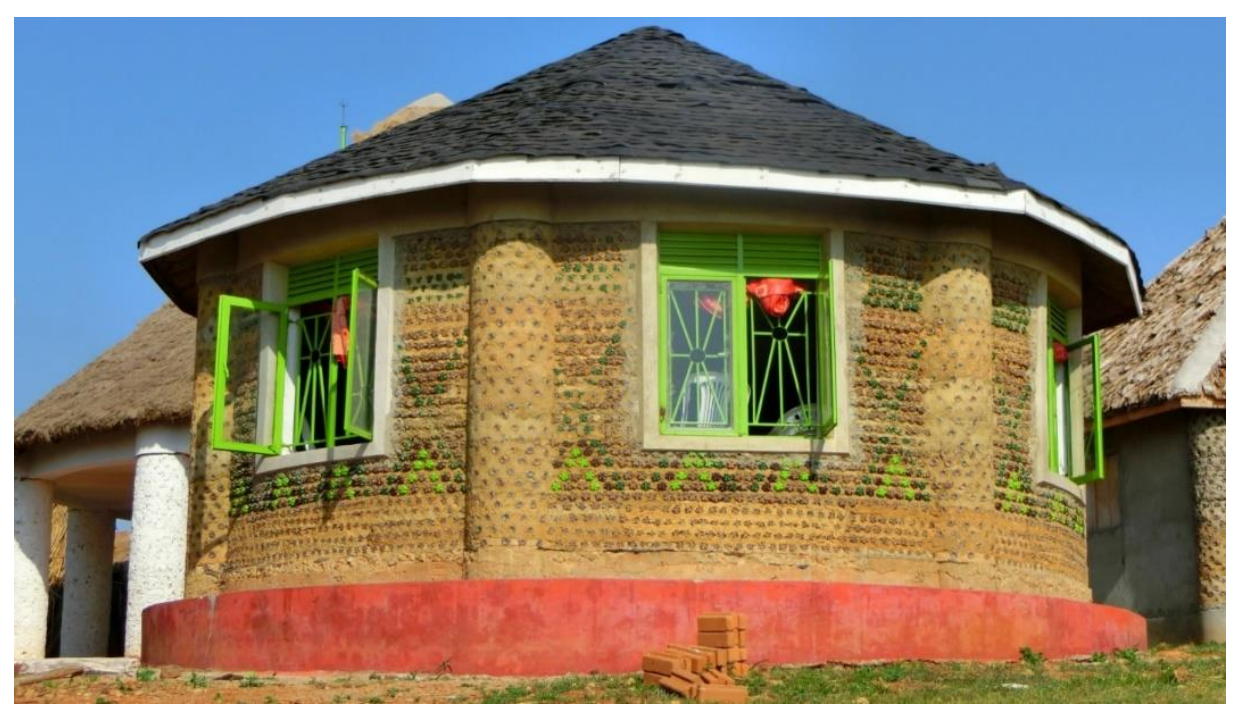

FIGURE 1: A house constructed out of plastic waste bottles in Uganda. (Kavuma, 2021) 
The companies prototype wall tiles are more than twice as strong as conventional ceramic alternatives and their prototype pavers are more than 14 times stronger than concrete pavers. Both can be sold at market rates for a $€ 1.77$ profit per square metre (Manglof, 2020). Such initiatives have been able to significantly reduce the presence and effect of plastic wastes in urban centres regardless of the notable challenges they face. Plastic packaging waste can be used to remanufacture new value products such as bricks and composites, furniture, clothes and foot wear and in road construction (Khan et al., 2016). In addition, HDPE is recycled in Uganda to feed local manufacturers of products like jerry cans, basins and bottle caps. All these investments cut environmental pollution and encourage cleaning up of towns and cities plastic wastes such as plastic bags and bottles. It is also expected to encourage people who are engaged in dry waste cleaning services by giving them additional income from collecting these wastes and selling it to the companies. However, they are also still covering small margins of the plastic waste imported and produced in Uganda. The government can get involved by building its own larger material handling centres or supporting the private players with funds, land and media access across the country. This would give the country a fighting chance against plastic waste pollution since it would involve the government, academia, private sector and the people that consume the products.

\section{CONCLUSIONS}

As modernity continues to take over in Uganda, packaging has also developed especially in the area of food from not only protecting food from the environment but also ensuring safety and high-quality products to the consumers. Plastic packaging is so important in food waste reduction since it extends the shelf life of the food and also helps reduce transportation costs by bringing the packaging weight down. It has been observed that a lot of plastic packaging (approximately 79\%) is dumped into the landfills or on the environment, $12 \%$ has been incinerated while only $9 \%$ is said to have been recycled. This proves the threat plastic packaging has got on the environment and the life of human beings. This also has great impact on today's economy, since $95 \%$ of the plastic packaging value which is equivalent to $\$ 80-120$ billion is lost annually after their first use of cycle. More so $32 \%$ of the plastic packaging escapes collection systems which causes significant costs to the economy because it affects natural systems like oceans and clogs urban infrastructure. Considering all the strategies being put in place to reduce the impact plastic packaging like strengthening markets for recycling, social awareness and encouraging production of ecofriendly plastics. This paper proposes complementing all these with proper education on waste management in Uganda. With education inclusion, there's a $75 \%$ chance of greater sustainability of all these waste reduction strategies since management systems are handled correctly throughout the whole process. Governments should also get more involved by building larger material handling sites and also supporting the smaller private owned plastic recycling businesses. Small incentives like grants, space allocation for collection centers at district, county and sub county level would also go a long way to ease the work of these companies consequently collectively reducing the scourge of plastic waste in Uganda.

\section{REFERENCES}

[1] Abel, A., Machado, D. S., Hempel, S., Rillig, M. C., Kloas, W., \& Zarfl, C. (2017). Microplastics as an emerging threat to terrestrial ecosystems. Global Change Biology, (September).

https://doi.org/10.1111/gcb.14020
[2] African Union. (2017). State of Africa's Population 2017: Keeping Rights of Girls, Adolescents and Young Women at the Center of Africa's Demographic Dividend, (March).

[3] Aryampa, S., Maheshwari, B., Sabiiti, E., Bateganya, N. L., \& Bukenya, B. (2019). Status of waste management in the East African Cities: Understanding the drivers of waste generation, collection and disposal and their impacts on Kampala City's sustainability. Sustainability, 11(19), 5523.

[4] Babayemi, J. O., Nnorom, I. C., Osibanjo, O., \& Weber, R. (2019). Ensuring sustainability in plastics use in Africa: consumption, waste generation, and projections. Environmental Sciences Europe, 31(1), 1-20.

[5] Bashir, N. H. (2013). Plastic problem in Africa. Japanese Journal of Veterinary Research, 61(Supplement), S1-S11.

[6] CARE. (2019). Request for Proposal Invitation to Innovation Challenge on: Plastic Waste Recycling and Local Manufacturing of Products made from the Recycled Plastic in Uganda Refugee Settlement, 1-12.

[7] Center for Disease Control. (2006). FoodNet Surveillance Report for 2004 (Final Report).

[8] Council, A. C. (2019). Plastic Packaging Flexes.

[9] Danielsson, M. (2017). The Plastic Bag Ban in Rwanda: Local Procedures and Successful Outcomes, (January).

[10] Debrah, J. K., Vidal, D. G., \& Dinis, M. A. P. (2021). Innovative use of plastic for a clean and sustainable environmental management: Learning cases from Ghana, Africa. Urban Science, 5(1), 12.

[11] Development, O. for E. C. and. (2018). Improving Plastics Management: Trends, policy responses, and the role of international co-operation and trade, (12), 24.

[12] Economic Research Department. (2019). Plastic packaging in the food sector Six ways to tackle the plastic puzzle, (December).

[13] Elliott, T., Ettlinger, S., Blacklaws, K., Kibara, S., Ndirangu, E., \& Chege, W. (2018). Plastic Packaging Waste Flows in Kenya. Eunomia Research \& Consulting Ltd, 37.

[14] Geyer, R., Jambeck, J. R., \& Law, K. L. (2017). Production, use, and fate of all plastics ever made, (July), 25-29.

[15] Hopewell, J., Dvorak, R., \& Kosior, E. (2009). Plastics recycling: challenges and opportunities, 2007, 21152126. https://doi.org/10.1098/rstb.2008.0311

[16] Khan, I. M., Kabir, S., Alhussain, M. A., \& Almansoor, F. F. (2016). Asphalt Design using Recycled Plastic and Crumb-rubber Waste for Sustainable Pavement Construction. Procedia Engineering, 145, 1557-1564. https://doi.org/10.1016/j.proeng.2016.04.196

[17] Kornher, L., \& von Braun, J. (2020). EU common agricultural policy-Impacts on trade with Africa and African agricultural development. Available at SSRN 3613628.

[18] Kosuth, M., Mason, S. A., \& Wattenberg, E. V. (2019). Anthropogenic contamination of tap water, beer, and sea salt, (July). https://doi.org/10.7910/DVN/IFCKDL.Funding 
[19] Kotsanopoulos, K. V., \& Arvanitoyannis, I. S. (2017). The role of auditing, food safety, and food quality standards in the food industry: A review. Comprehensive Reviews in Food Science and Food Safety, 16(5), 760-775.

[20] Liu, X., Yin, Y., Xu, X., Tang, Q., \& Cui, H. (2018) Integrated environmental risks. In Atlas of environmental risks facing china under climate change (pp. 205-223). Springer, Singapore.

[21] Maharan, T., \& Negi, Y. (2007). Review Article: Recycling of Polystyrene This article was downloaded by: [ Indest open Consortium] Access details: Access Details: [ subscription number 934204318] PolymerPlastics Technology and Engineering Review Article: Recycling of Polystyrene, (January 2016). https://doi.org/10.1080/03602550701273963

[22] Mugisha, J., \& Diiro, G. (2015a). Households' Responsiveness to Government Ban on Polythene Carrier Bags in Uganda. Journal of Agriculture and Environmental Sciences, 4(1), 216-224. https://doi.org/10.15640/jaes.v4n1a27

[23] Mugisha, J., \& Diiro, G. (2015b). Households Responsiveness to Government Ban on Polythene Carrier Bags in Uganda, 4(1), 216-224. https://doi.org/10.15640/jaes.v4n1a27

[24] Mwanza, B. G., \& Mbohwa, C. (2017). Major obstacles to sustainability in the plastic industry. Procedia Manufacturing, 8, 121-128.

[25] Ojha, A., Sharma, A., Sihag, M., \& Ojha, S. (2015). Food packaging - materials and sustainability-A review Food packaging - materials and sustainability-A review, (January). https://doi.org/10.5958/09760741.2015 .00028 .8

[26] Porta, R. (2019). The plastics sunset and the bioplastics sunrise.

[27] Raheem, D. (2013). Application of plastics and paper as food packaging materials-An overview. Emirates Journal of Food and Agriculture, 177-188.

[28] Raja, A., \& Murali, A. (2011). Conversion of plastic wastes into fuels. Journal of Materials science and engineering $B, 1(1)$, 86-89.

[29] Rayne, S. (2008). The need for reducing plastic shopping bag use and disposal in Africa. African Journal of Environmental Science and Technology, 3(3), 7-9.

[30] Sherrington, C., Hogg, D., Darrah, C., \& Hann, S. (2014). Exploring the Indirect Costs of Litter in Scotland.

[31] Tucker, P. G., Goldman, R., Woolf, A., \& Shannom, M. (2016). ATSDR Case Studies in Environmental Medicine Principles of Pediatric Environmental Health.

[32] Vanapalli, K. R., Sharma, H. B., Ranjan, V. P., Samal, B., Bhattacharya, J., Dubey, B. K., \& Goel, S. (2021). Challenges and strategies for effective plastic waste management during and post COVID-19 pandemic. Science of The Total Environment, 750, 141514
[33] Wangwe, S., Mmari, D., Aikaeli, J., Rutatina, N., Mboghoina, T., \& Kinyondo, A. (2014). The performance of the manufacturing sector in Tanzania: Challenges and the way forward (No. 2014/085). WIDER Working Paper.

[34] World Environment Day. (2020). World Environment Day 2020: A Practical guide.

[35] Wrona, M., \& Ner, C. (2020). Analytical Approaches for Analysis of Safety of Modern Food Packaging: A Review.

[36] Ggoobi, R. (2020). Uganda's post-covid-19 industrial policy strategy.

[37] Owusu, P. A., Banadda, N., \& Kiggundu, N. (2017). Mass Balance of Plastic Waste Conversion to Fuel Oil-A case in Uganda. Journal of Sustainable Development, $10(6), 41$.

[38] Vivo Energy Uganda. (2021). Vivo Energy Uganda launches a plastic waste collection initiative at Shell service stations. 29 Sep 2021.

https://www.vivoenergy.com/Where-weOperate/Uganda/Media-Centre/Press-

Releases/Details/Vivo-Energy-Uganda-launchesplastic-waste-collection-initiative-at-Shell-servicestations. Accessed on 30th. December. 2021

[39] Manglof, L. (2020). Ugandan project recycles plastic waste into construction materials. 6th July 2020. https://www.springwise.com/innovation/healthwellbeing/takataka-plastics-waste-face-shields. Accessed on 30th. December. 2021.

[40] Nampijja, D. (2016). Plastic Bags in Uganda. A Threat to Human Health and the Environment. Makerere University. http://cees. mak. ac. ug/sites/default/files/Series_Plastic_bags. pdf.

[41] UN Environment Programme (UNEP). (2021). Uganda joins Clean Seas Campaign to keep plastic pollution out of its lakes and rivers. 25th June. 2021. https://www.unep.org/news-and-stories/pressrelease/uganda-joins-clean-seas-campaign-keepplastic-pollution-out-its. Accessed on 30th. December. 2021.

[42] The Natural Resources Stewardship Programme (NatuReS). (2021). Exploring PET plastic waste flows in Greater Kampala_ A baseline study conducted under the GKMA PET Plastic Recycling Partnership. July 19, 2021. https://naturestewardship.org/countries/uganda/pet-plasticwaste-flows-in-greater-kampala/. Accessed on 30th. December. 2021.

[43] Kavuma, J. (2021). How One Young Man's Childhood Experiences Spurred the Movement to Build Homes Out of Plastic Bottles in Uganda. Upcycle Africa. June $11,2021$. https://upcycleafrica.org/2021/06/11/meetthemb1 00-johnmary-kavuma-co-founder-ceo-upcycleafrica/. Accessed on 30th. December. 2021. 